\title{
BMJ Mortality following unemployment Open during an economic downturn: Swedish register-based cohort study
}

\author{
Scott Montgomery, ${ }^{1,2,3}$ Ruzan Udumyan, ${ }^{1,2}$ Anders Magnuson, ${ }^{1}$ Walter Osika, ${ }^{4}$ \\ Per-Ola Sundin, ${ }^{2,5}$ David Blane ${ }^{6}$
}

To cite: Montgomery S, Udumyan R, Magnuson A, et al. Mortality following unemployment during an economic downturn: Swedish register-based cohort study. BMJ Open 2013;3:e003031.

doi:10.1136/bmjopen-2013003031

- Prepublication history for this paper is available online. To view these files please visit the journal online (http://dx.doi.org/10.1136/ bmjopen-2013-003031).

Received 10 April 2013

Revised 4 June 2013

Accepted 12 June 2013

This final article is available for use under the terms of the Creative Commons Attribution Non-Commercial 3.0 Licence; see http://bmjopen.bmj.com

For numbered affiliations see end of article.

\section{Correspondence to}

Professor Scott Montgomery; scott.montgomery@orebroll. se

\section{ABSTRACT}

Objective: To investigate if unemployment during an economic downturn is associated with mortality, even among men with markers of better health (higher cognitive function scores and qualifications), and to assess whether the associations vary by age at unemployment.

Design: Longitudinal register-based cohort study. Setting: Study entry was in 1990 and 2001 when Sweden was entering periods of significant economic contraction.

Participants: A representative sample of men from the general population ( $n=234782$ ) born between 1952 and 1956 who participated in military conscription examinations. Men in receipt of disability or sickness benefit at study entry were excluded.

Main outcome measure: All-cause mortality. Results: Unemployment compared with employment in 1991 (ages 34-38 years) produced adjusted HRs (with 95\% Cls) for all-cause mortality (3651 deaths) during follow-up to 2001 and after stratification by education of 2.35 (1.99 to 2.76) for compulsory education, 2.25 (1.97 to 2.58) for up to 3 years postcompulsory education and 1.90 (1.40 to 2.57 ) for more than 3 years postcompulsory education. When unemployment was compared with employment in 2001 (ages 45-49 years) with followup to 2010 , the pattern of mortality risk (4271 deaths) stratified by education was reversed, producing adjusted HRs of 2.81 (2.47 to 3.21) for compulsory education, 2.87 (2.58 to 3.19) for up to 3 years postcompulsory education and 3.44 (2.78 to 4.25 ) for more than 3 years postcompulsory education. Interaction testing confirmed effect modification by age/period ( $p=0.003$ ). The degree of gradient reversal was slightly less pronounced after stratification by cognitive function but produced a similar pattern of results $(p=0.004)$.

Conclusions: Unemployment at older ages is associated with greater mortality risk than at younger ages, with the greatest relative increase in risk among men with markers of better health, suggesting the greater vulnerability of all older workers to unemployment-associated exposures.

\section{ARTICLE SUMMARY}

\section{Article focus}

- Unemployment is associated with poor health and excess mortality, which is explained by a variety of mechanisms.

- Higher qualifications and better cognitive function are associated with better health.

- Economic adversity has been associated with disproportionate damage to health among individuals who were previously advantaged, so unemployment may have this effect among those with higher qualifications and better cognitive function.

\section{Key messages}

- Unemployment in later working life is more likely to be associated with damage to health among those with better cognitive function and qualifications than unemployment at a younger age.

- This emphasises the importance of supporting all older workers who become unemployed, including those with characteristics usually associated with better health.

Strengths and limitations of this study

- The study benefits from use of a large longitudinal cohort with prospectively recorded information.

- Unemployment is only measured at a limited number of time points, so the study cannot examine the duration of exposure.

- The use of Swedish military conscription data limited the study to men, so it is not known if the findings would be similar among women.

\section{INTRODUCTION}

Economic recession and associated austerity measures result in increased unemployment, which is linked with poorer health and excess mortality through a variety of mechanisms. ${ }^{1}$ During a recession, unemployment may be experienced by a broader spectrum of the working population rather than just more disadvantaged individuals. Does this 
atypical pattern of exposure to unemployment have unexpected health consequences?

Better cognitive function and higher levels of education are associated with better health and reduced mortality risk in later life..$^{2-4} \mathrm{~A}$ review of intelligence in youth and all-cause mortality highlighted the likely importance of economic and social characteristics in adulthood in explaining the association. ${ }^{3}$ Further clarification may be gained by examining how economic disadvantage such as unemployment modifies the association of intelligence in adolescence with adult mortality risk.

Better cognitive function and educational attainment confer protection against unemployment and facilitate a more rapid transition back to employment from unemployment, thus reducing the duration of exposure to unemployment-associated adversity. Therefore, health following experience of unemployment should be better among those with better cognitive function and the more highly qualified. However, in earlier studies we demonstrated that unexpected financial adversity is disproportionately damaging to health, ${ }^{5-7}$ where adult economic disadvantage was experienced among those with pre-existing markers of better health and economic potential signalled by markers of childhood advantage. The disappointment paradox ${ }^{7}$ hypothesises that when individuals with greater potential and expectations encounter economic adversity in adulthood, the experience is relatively unexpected, resulting in higher levels of stress and depression and thus also damaging to other aspects of health. This is consistent with the finding that psychological distress associated with unemployment was reported more frequently among white-collar than blue-collar workers. ${ }^{8}$

Unexpected economic adversity even among those with greater personal resources may be particularly damaging at older ages, ${ }^{9}$ making obtaining another job at an equivalent level more difficult. As the mechanisms linking cognitive function and education with mortality may not be identical, ${ }^{2}$ we examined these measures separately. This study uses Swedish register data to examine associations of unemployment with mortality among a cohort of men born between 1952 and 1956, as well as to test the hypothesis that unemployment disproportionately eliminates health potential associated with better cognitive function and higher qualifications and that the effect varies by age. Unemployment was assessed in 1990 and 2001 when the men were aged 34-38 and 4549 years, respectively. In 1990, Sweden was entering a period of deep economic recession and another period of significant economic contraction was beginning in 2001.

\section{METHODS}

\section{Study population}

The cohort comprised all men born between 1 January 1952 and 31 December 1956 who were included in the
Swedish Military Conscription Register. ${ }^{10}{ }^{11}$ At this time, the majority of male Swedish citizens participated in the assessment for compulsory military service that took place in late adolescence and fewer than $4 \%$ of men were not involved due to chronic illness or disability. The assessments were between 1970 and 1975, and the majority was between ages 18 and 19 years, with a small number after this time at later ages. A total of 284198 men were identified and 2564 were excluded due to data inconsistencies such as errors in the personal identification number, female sex or uncertain vital status. We then excluded 225 men from the analysis with improbable measures at the conscription assessment: height less than $144 \mathrm{~cm}(\mathrm{n}=39)$, body mass index (BMI) below $15 \quad(n=134)$, weight above $178 \mathrm{~kg}(\mathrm{n}=9)$, systolic blood pressure below 50 or above $230 \mathrm{~mm} \mathrm{Hg} \quad(\mathrm{n}=33)$ and diastolic blood pressure below 30 or above $135 \mathrm{~mm} \mathrm{Hg}(\mathrm{n}=12)$. This resulted in a sample of 272768 men with data at the start of follow-up in December 1990. We then excluded 35161 men with missing data for: census (18 178), education (2440) or the conscription assessments $(28483)$ that may have resulted from loss of records. The sample available for the main analysis comprised 234782 men.

\section{Measures}

The conscription examination in late adolescence provided the following measures. Height and weight were used to calculate BMI categories (table 1). Systolic and diastolic blood pressures were measured after rest in recumbent men using a sphygmomanometer. Physical working capacity was assessed using an electronically braked ergonometer for the maximum load sustained for $6 \mathrm{~min}$, or an estimate was derived from a nomogram for a shorter duration. Cognitive testing covered four domains: linguistic understanding (40 questions), spatial recognition (identifying geometric shapes), general knowledge (40 questions) and ability to follow mechanical instructions (problems presented as diagrams requiring knowledge of mechanics and basic physics). The results of the cognitive function tests were transformed into a single score with a value on a normalised standard scale ranging from 1 to 9 . The conscripts underwent a psychological examination to assess their potential ability to cope with warfare and thus provided an indication of their stress resilience, producing a score $1-9$, which we grouped as 1-3, 4-6 and 7-9. Details of the test are available in Swedish, ${ }^{12}$ but it has been used in research reported in English. ${ }^{13}$ The medical assessment produced a score of 0-9 to indicate the severity of any medical problem, such that 9 indicated no problem, with a decreasing score indicating increasing severity to 0 , indicating a very significant problem, while a score of 1 indicated a potential but illdefined problem $(n=22)$.

Statistics Sweden provided socioeconomic and demographic data using the registers they administer, ${ }^{14}$ including information on vital status and emigration from the Total Population register. Childhood social and material 
Table 1 Population characteristics and subsequent unemployment in 1990 and 2001

\begin{tabular}{|c|c|c|c|c|c|c|}
\hline & \multicolumn{3}{|l|}{1990} & \multicolumn{3}{|l|}{2001} \\
\hline & $\begin{array}{l}\text { Employed } \\
\mathrm{N}(\%) \\
{ }^{\star} \text { Mean (SD) }\end{array}$ & $\begin{array}{l}\text { Unemployed } \\
\mathrm{N}(\%) \\
{ }^{*} \text { Mean (SD) }\end{array}$ & $\begin{array}{l}\text { Disability } \\
\text { pension } \\
\mathrm{N}(\%) \\
{ }^{*} \text { Mean (SD) } \\
\end{array}$ & $\begin{array}{l}\text { Employed } \\
\mathrm{N}(\%) \\
{ }^{*} \text { Mean (SD) }\end{array}$ & $\begin{array}{l}\text { Unemployed } \\
\mathrm{N}(\%) \\
{ }^{*} \text { Mean (SD) }\end{array}$ & $\begin{array}{l}\text { Disability } \\
\text { pension } \\
\mathrm{N}(\%) \\
{ }^{*} \text { Mean (SD) } \\
\end{array}$ \\
\hline \multicolumn{7}{|l|}{ Parental SEI 1960} \\
\hline Manual workers & $91878(41.5)$ & $5274(40.2)$ & $1380(46.9)$ & 82938 (41.2) & $7413(43.6)$ & 5049 (47.3) \\
\hline Agricultural workers & 8592 (3.9) & 471 (3.6) & $120(4.1)$ & 7693 (3.8) & $743(4.4)$ & $507(4.7)$ \\
\hline Farm owners/managers & $22510(10.2)$ & $948(7.2)$ & $206(7.0)$ & 20931 (10.4) & $1373(8.1)$ & 770 (7.2) \\
\hline Office workers & $61748(27.9)$ & 3774 (28.7) & $684(23.2)$ & $56698(28.1)$ & $4199(24.7)$ & $2389(22.4)$ \\
\hline Business owners/managers & $23701(10.7)$ & 1569 (12.0) & $263(8.9)$ & $21690(10.8)$ & $1893(11.1)$ & $982(9.2)$ \\
\hline Others/unknown & 13105 (5.9) & $1093(8.3)$ & 291 (9.9) & $11557(5.7)$ & $1362(8.0)$ & $986(9.2)$ \\
\hline \multicolumn{7}{|l|}{ Household crowding, 1960} \\
\hline$\leq 2$ people/room & $173804(78.5)$ & $9883(75.3)$ & 2085 (70.8) & $159131(79.0)$ & $12412(73.1)$ & $7538(70.6)$ \\
\hline$>2$ people/room & $47730(21.5)$ & $3246(24.7)$ & 859 (29.2) & $42376(21.0)$ & $4562(26.9)$ & $3145(29.4)$ \\
\hline \multicolumn{7}{|l|}{ BMI categories $\left(\mathrm{kg} / \mathrm{m}^{2}\right)$} \\
\hline Underweight $(<18.5)$ & $25476(11.5)$ & $1664(12.7)$ & $481(16.3)$ & 22999 (11.4) & $2106(12.4)$ & 1525 (14.3) \\
\hline Normal weight $(18.5,<25)$ & $179381(81.0)$ & $10456(79.6)$ & 2234 (75.9) & $163723(81.2)$ & 13451 (79.2) & $8142(76.2)$ \\
\hline Overweight $(25.0,<30)$ & $14536(6.6)$ & $833(6.3)$ & $183(6.2)$ & $12955(6.4)$ & $1191(7.0)$ & $837(7.8)$ \\
\hline Obese $(\geq 30.0)$ & $2141(1.0)$ & $176(1.3)$ & $46(1.6)$ & $1839(0.9)$ & $235(1.4)$ & $179(1.7)$ \\
\hline \multicolumn{7}{|l|}{ Summary disease score } \\
\hline Very significant problem (0) & $10560(4.8)$ & $1613(12.3)$ & $897(30.5)$ & $8212(4.1)$ & $1920(11.3)$ & $2159(20.2)$ \\
\hline Significant problem (2-3) & $6468(2.9)$ & $586(4.5)$ & $249(8.5)$ & $5481(2.7)$ & $782(4.6)$ & $698(6.5)$ \\
\hline Fairly significant (4-5) & $16671(7.5)$ & $1061(8.1)$ & $246(8.4)$ & $14782(7.3)$ & $1548(9.1)$ & $1032(9.7)$ \\
\hline No serious problem (6-8) & $88816(40.1)$ & $4832(36.8)$ & $830(28.2)$ & $81106(40.2)$ & $6472(38.1)$ & 3774 (35.3) \\
\hline No diagnosis (9) & 98997 (44.7) & 5037 (38.4) & $722(24.5)$ & 91909 (45.6) & 6260 (36.9) & 3018 (28.3) \\
\hline III-defined problem (1) & $22(0.0)$ & $0(0.0)$ & $0(0.0)$ & $18(0.0)$ & $1(0.0)$ & $2(0.0)$ \\
\hline \multicolumn{7}{|l|}{ Stress resilience } \\
\hline Low (1-3) & 45221 (20.4) & 4407 (33.6) & $1750(59.4)$ & $38222(19.0)$ & 5927 (34.9) & $5108(47.8)$ \\
\hline Moderate (4-6) & 122546 (55.3) & $6092(46.4)$ & 1005 & $112943(56.0)$ & $8227(48.4)$ & $4494(42.1)$ \\
\hline High (7-9) & 53767 (24.3) & $2630(20.0)$ & $189(6.4)$ & $50342(25.0)$ & $2829(16.7)$ & $1081(10.1)$ \\
\hline \multicolumn{7}{|l|}{ Education } \\
\hline Compulsory & $54698(24.7)$ & $3634(27.7)$ & $1345(45.7)$ & $48367(24.0)$ & 5254 (30.9) & 4089 (38.3) \\
\hline$\leq 3$ years postcompulsory & 103251 (46.6) & 6595 (50.2) & $1388(47.1)$ & 93225 (46.3) & 9019 (53.1) & 5577 (52.2) \\
\hline$>3$ years postcompulsory & $63585(28.7)$ & $2900(22.1)$ & $211(7.2)$ & $59915(29.7)$ & $2710(16.0)$ & $1017(9.5)$ \\
\hline Height* & $178.7(6.4)$ & $178.4(6.5)$ & $177.7(6.7)$ & $178.8(6.4)$ & $178.1(6.5)$ & $177.8(6.6)$ \\
\hline Physical working capacity* & $6.3(1.8)$ & $6.0(1.8)$ & $5.6(1.8)$ & $6.4(1.8)$ & $6.0(1.8)$ & $5.8(1.8)$ \\
\hline Systolic blood pressure* & $127.7(11.1)$ & $127.0(11.1)$ & $128.1(11.3)$ & $127.7(11.1)$ & $127.3(11.0)$ & $127.8(11.4)$ \\
\hline Diastolic blood pressure* & $71.6(8.6)$ & $71.7(8.6)$ & $73.0(9.0)$ & $71.6(8.6)$ & $71.8(8.8)$ & $72.3(8.8)$ \\
\hline Cognitive function* & $5.2(2.0)$ & $5.0(2.0)$ & $3.82(2.1)$ & $5.3(1.9)$ & $4.7(2.0)$ & $4.1(2.0)$ \\
\hline Total (row percentages) & 221534 (93.2) & $13129(5.5)$ & 2944 (1.2) & 201507 (87.9) & $16983(7.4)$ & $10683(4.7)$ \\
\hline
\end{tabular}


circumstances were estimated using data from the 1960 census, where the head of the household's occupation was characterised as manual, agricultural, farm owners/ managers, office workers, business owners/managers and others. The person per room ratio was divided into quarters of its distribution. The Longitudinal database of Education, Income and Occupation (LISA) was used to obtain information on the level of attained education in 1990, employment status in 1985, as well as employment status and receipt of disability/chronic disease benefits in 1990 and 2001. Attained education-based on the duration of education required for the qualification-was divided into three categories: compulsory (up to 9 years), up to 3 years postcompulsory and over 3 years postcompulsory. Unemployment was recorded on a single day in November in 1990 and 2001. Receipt of disability/chronic disease benefits at any time earlier in the year was recorded.

The Cause of Death Register ${ }^{15}$ provided International Classification of Diseases (ICD) codes on causes of death, including suicide, where we also included undetermined intent as possible suicide.

\section{Statistical analysis}

Cox regression was used to examine the association of unemployment (compared with employment) with subsequent mortality risk over two periods: unemployment in 1990 with follow-up to 2001 and unemployment in 2001 with follow-up to 2010. Men who received disability/chronic disease benefits at entry to either follow-up period were excluded from analysis in that period. Follow-up was to death, emigration or the end of the study period, whichever occurred first. The analysis was adjusted for socioeconomic index (SEI) of parents and household crowding in 1960, and the following conscription measures: BMI in categories as in table 1, height (continuous), physical working capacity (continuous), systolic and diastolic blood pressure (in fifths), summary cognitive score (continuous), education, disease severity score (categorised as $0,1,2-3,4-5,6-8$ and 9). The analysis was also adjusted for employment status in 1985 (and 1990 for the later follow-up periods) and region of residence. Attained age was used as the underlying time scale for all models to achieve the most efficient adjustment for age. The analyses were stratified by the cognitive function score divided into equal thirds of its distribution and then by the three category education variable. Further analyses excluded mortality due to suicide (including where the cause of death was recorded as undetermined intent). Analyses then excluded the first 4 years of follow-up after 1990 and 2001 to allow for the 'selection to wear off'. ${ }^{16} 17$

A Cox regression model with follow-up over the entire study period (1990-2010) assessed whether period (age) of unemployment (1990 or 2001) is an effect modifier for the association with mortality for the combination of unemployment with cognitive function or with education. Unemployment was modelled as a time-dependent covariate and the analysis was adjusted for the potential confounding factors described above.

The statistical software used was Stata V.12/SE for Windows (StataCorp, College Station, Texas, USA). Tests were two-sided and statistical significance was defined as $\mathrm{p}<0.05$ and $95 \%$ CIs that do not include 1.00 .

\section{Results}

All the characteristics investigated were statistically significantly associated with unemployment in 1990 and 2001 (table 1) and as they all produced $p$ values of less than 0.001, the $\mathrm{p}$ values are not presented. Unemployment and receipt of a disability pension in both periods were associated with lower parental SEI, greater household crowding, BMI indicating underweight or obesity, diagnoses of more severe diseases at conscription, low stress resilience, lower level qualifications, shorter stature, lower physical working capacity and lower cognitive function score. Higher diastolic blood pressure was associated with unemployment and disability pension, but the pattern is more complex for systolic blood pressure. The total number unemployed in 2001 was greater than in 1990 and the number on disability/chronic sickness benefit was notably greater in 2001. Overall, the distribution of educational attainment and cognitive function score among the employed was very similar between the two periods, but a higher proportion of those who experienced unemployment during the second period had lower qualifications and cognitive function scores.

During the period 1990-2001, unemployment compared with employment in 1990 was associated with a statistically significantly raised risk of mortality in each of the cognitive function and education strata, both before and after adjustment for the potential confounding factors (table 2). Patterns of association for unemployment with mortality are similar whether stratified by $\operatorname{cog}$ nitive function or by education. The results are graded by cognition and education, with the highest unemployment-related mortality risk among men with the lowest cognitive function scores and education. Exclusion of deaths due to suicide altered the gradient of risk between the first two strata, but men with the highest cognitive function scores and qualifications remained at the lowest risk of mortality if they experienced unemployment. Some reduction in the magnitude of risk, but without loss of statistical significance, was observed when deaths during the first 4 years of follow-up were excluded to allow for the 'wearing off' of direct health selection.

During the period 2001-2010, unemployment compared with employment in 2001 was associated with a statistically significantly raised risk of mortality in each of the education strata both before and after adjustment for the potential confounding factors (table 3). Patterns of association for unemployment with mortality are similar whether stratified by cognitive function or by 
Table 2 Unemployment in 1990 and mortality risk (1990-2001) stratified by level of cognitive function and education

\begin{tabular}{|c|c|c|c|c|c|c|}
\hline & $\begin{array}{l}\text { Number of } \\
\text { events/number } \\
\text { of men }\end{array}$ & $\begin{array}{l}\text { Mortality rates } / 1000 \\
\text { person-years }(95 \% \mathrm{Cl})\end{array}$ & $\begin{array}{l}\text { Unadjusted HR } \\
(95 \% \mathrm{CI})^{\star}\end{array}$ & $\begin{array}{l}\text { Adjusted HR } \\
(95 \% \mathrm{Cl}) \dagger\end{array}$ & $\begin{array}{l}\text { Excluding suicide } \\
\text { HR }(95 \% \mathrm{Cl}) \dagger\end{array}$ & $\begin{array}{l}\text { Selection wearing off } \\
\text { HR }(95 \% \mathrm{Cl}) \dagger ’ \ddagger\end{array}$ \\
\hline \multicolumn{7}{|l|}{ Cognitive function } \\
\hline \multicolumn{7}{|c|}{ Cognitive score $1-3$} \\
\hline Employed & $846 / 43637$ & 1.78 (1.67 to 1.91$)$ & Ref. & Ref. & Ref. & Ref. \\
\hline Unemployed & $198 / 3206$ & 5.87 (5.10 to 6.74$)$ & 3.33 (2.85 to 3.89$)$ & 2.43 (2.06 to 2.88$)$ & 2.40 (1.99 to 2.90$)$ & 2.25 (1.83 to 2.75$)$ \\
\hline \multicolumn{7}{|c|}{ Cognitive score $4-6$} \\
\hline Employed & $1655 / 117393$ & $1.30(1.24$ to 1.36$)$ & Ref. & Ref. & Ref. & Ref. \\
\hline Unemployed & $281 / 6799$ & 3.96 (3.52 to 4.45$)$ & 3.08 (2.72 to 3.50$)$ & 2.33 (2.04 to 2.67$)$ & 2.50 (2.15 to 2.90$)$ & 2.33 (1.98 to 2.74$)$ \\
\hline \multicolumn{7}{|c|}{ Cognitive score $7-9$} \\
\hline Employed & $604 / 60504$ & $0.92(0.85$ to 1.00$)$ & Ref. & Ref. & Ref. & Ref. \\
\hline Unemployed & $67 / 3124$ & 2.13 (1.68 to 2.71$)$ & 2.33 (1.81 to 3.00$)$ & 1.85 (1.42 to 2.40$)$ & 1.80 (1.33 to 2.43$)$ & 1.53 (1.08 to 2.16$)$ \\
\hline \multicolumn{7}{|l|}{ Education } \\
\hline \multicolumn{7}{|c|}{ Compulsory education } \\
\hline Employed & $1015 / 54698$ & $1.71(1.60$ to 1.81$)$ & Ref. & Ref. & Ref. & Ref. \\
\hline Unemployed & $208 / 3634$ & 5.47 (4.78 to 6.27$)$ & 3.25 (2.80 to 3.77$)$ & 2.35 (1.99 to 2.76$)$ & 2.31 (1.93 to 2.76$)$ & 2.23 (1.83 to 2.72$)$ \\
\hline \multicolumn{7}{|c|}{$\leq 3$ years postcompulsory education } \\
\hline Employed & $1524 / 103251$ & 1.36 (1.29 to 1.43$)$ & Ref. & Ref. & & \\
\hline Unemployed & $291 / 6595$ & 4.21 (3.76 to 4.73$)$ & 3.14 (2.77 to 3.56$)$ & 2.25 (1.97 to 2.58$)$ & 2.40 (2.06 to 2.80$)$ & 2.19 (1.86 to 2.58$)$ \\
\hline \multicolumn{7}{|c|}{$>3$ years postcompulsory education } \\
\hline Employed & $566 / 63585$ & $0.83(0.76$ to 0.90$)$ & Ref. & Ref. & Ref. & Ref. \\
\hline Unemployed & $47 / 2900$ & 1.61 (1.21 to $2-15)$ & 1.98 (1.47 to 2.66$)$ & 1.90 (1.40 to 2.57$)$ & 1.87 (1.32 to 2.66$)$ & 1.67 (1.13 to 2.46$)$ \\
\hline
\end{tabular}


Table 3 Unemployment in 2001 and mortality risk (2001-2010) stratified by level of cognitive function and education

\begin{tabular}{|c|c|c|c|c|c|c|}
\hline & $\begin{array}{l}\text { Number of } \\
\text { events/number of men }\end{array}$ & $\begin{array}{l}\text { Mortality rates } / 1000 \\
\text { person-years }(95 \% \mathrm{Cl})\end{array}$ & $\begin{array}{l}\text { Unadjusted } \\
\text { HR }(95 \% \mathrm{Cl})^{*}\end{array}$ & $\begin{array}{l}\text { Adjusted } \\
\text { HR }(95 \% \mathrm{Cl}) \dagger\end{array}$ & $\begin{array}{l}\text { Excluding suicide } \\
\text { HR }(95 \% \mathrm{Cl}) \dagger\end{array}$ & $\begin{array}{l}\text { Selection wearing off } \\
\text { HR }(95 \% \mathrm{Cl}) \dagger^{\prime} \ddagger\end{array}$ \\
\hline \multicolumn{7}{|l|}{ Cognitive function } \\
\hline \multicolumn{7}{|c|}{ Cognitive score $1-3$} \\
\hline Employed & $790 / 37222$ & 2.65 (2.47 to 2.84$)$ & Ref. & Ref. & Ref. & Ref. \\
\hline Unemployed & $328 / 5008$ & 8.41 (7.55 to 9.38$)$ & $3.19(2.80$ to 3.63$)$ & 2.76 (2.41 to 3.17 ) & $2.80(2.42$ to 3.24$)$ & 2.64 (2.22 to 3.15$)$ \\
\hline \multicolumn{7}{|c|}{ Cognitive score 4-6 } \\
\hline Employed & $1751 / 107598$ & 2.03 (1.94 to 2.13$)$ & Ref. & Ref. & Ref. & Ref. \\
\hline Unemployed & $500 / 8783$ & 7.35 (6.74 to 8.03$)$ & 3.63 (3.29 to 4.01$)$ & 3.03 (2.73 to 3.37 ) & $3.03(2.71$ to 3.40$)$ & 2.73 (2.36 to 3.15$)$ \\
\hline \multicolumn{7}{|c|}{ Cognitive score $7-9$} \\
\hline Employed & $759 / 56687$ & $1.67(1.56$ to 1.80$)$ & Ref. & Ref. & Ref. & Ref. \\
\hline Unemployed & 143/3192 & 5.83 (4.95 to 6.86$)$ & 3.49 (2.92 to 4.18$)$ & 2.85 (2.36 to 3.45 ) & 2.91 (2.38 to 3.56$)$ & 3.02 (2.37 to 3.85 ) \\
\hline \multicolumn{7}{|l|}{ Education } \\
\hline \multicolumn{7}{|c|}{ Compulsory education } \\
\hline Employed & $1000 / 48367$ & 2.58 (2.43 to 2.75$)$ & Ref. & Ref. & Ref. & Ref. \\
\hline Unemployed & $332 / 5254$ & $8.17(7.34$ to 9.10$)$ & 3.18 (2.81 to 3.60$)$ & 2.81 (2.47 to 3.21 ) & 2.84 (2.47 to 3.27 ) & 2.67 (2.25 to 3.18$)$ \\
\hline \multicolumn{7}{|c|}{$\leq 3$ years postcompulsory education } \\
\hline Employed & $1615 / 93225$ & 2.16 (2.06 to 2.27$)$ & Ref. & Ref. & Ref. & Ref. \\
\hline Unemployed & $533 / 9019$ & 7.61 (6.99 to 8.29$)$ & 3.54 (3.21 to 3.90$)$ & 2.87 (2.58 to 3.19$)$ & 2.91 (2.60 to 3.25$)$ & 2.67 (2.32 to 3.07$)$ \\
\hline \multicolumn{7}{|c|}{$>3$ years postcompulsory education } \\
\hline Employed & $685 / 59915$ & $1.43(1.33$ to 1.54$)$ & Ref. & Ref. & Ref. & Ref. \\
\hline Unemployed & $106 / 2710$ & 5.07 (4.19 to 6.13$)$ & 3.54 (2.88 to 4.34$)$ & 3.44 (2.78 to 4.25$)$ & 3.37 (2.68 to 4.23$)$ & 3.43 (2.58 to 4.54$)$ \\
\hline
\end{tabular}

*Age is the underlying timescale.

†Adjusted for parental SEI in 1960, household crowding in 1960, height, BMI, systolic and diastolic blood pressure, physical capacity score, summary disease score, cognitive function score or attained education and region of residence.

fDeaths during the first 4 years of follow-up are excluded.

BMI, body mass index; ref., reference category; SEI, socioeconomic index. 
education. In contrast with the earlier period, the unemployment-related mortality risk, when stratified by cognition or education, is reversed and consistently higher for the strata of those with the highest levels of cognitive function or education. It is noteworthy that the absolute rate of unemployment-related mortality is much more similar across the cognition and education strata, even though there is more of a gradient among the employed. In all the adjusted models, after exclusion of death by suicide, and after allowing 'selection to wear off', the gradient of unemployment-related mortality remains reversed or eliminated compared with the earlier period: those with the higher level cognitive function scores and qualifications had higher HRs for mortality associated with unemployment.

The interaction tests to assess effect modification by age/period are statistically significant for both cognitive function ( $\mathrm{p}=0.004)$ and education $(\mathrm{p}=0.003)$, consistent with higher mortality among men with better cognitive function or education when they experience unemployment at a later age.

\section{DISCUSSION}

Unemployment in 1990, when the men in this cohort were aged 34-38 years, was associated with all-cause mortality: men with poorer cognitive function test scores and lower-level educational attainment were at greater relative risk (measured by HRs) than men with higher qualifications. Unemployment in 2001, when the men were aged 45-49 years, was also associated with subsequent mortality, but the gradient was reversed such that the more intelligent and more highly qualified men were at a greater relative risk of mortality following unemployment. The gradient of the absolute unemployment-associated mortality rate, across cognition and education strata, was attenuated substantially by unemployment at an older age in 2001.

Previous research using data from the USA found that low income was a greater relative risk for ischaemic heart disease and depression among individuals with markers of a relatively privileged childhood and higher qualifications. ${ }^{5}$ Data from older adults in Britain revealed that similar economic adversity eliminated the lower depression risk associated with markers of earlier advantage. ${ }^{6}$ We hypothesised that this unexpected adversity results in a form of disappointment, thus increasing the risk of disease through behavioural change and the systemic consequences of stress. This study is an extension of the disappointment paradox concept but uses longitudinal rather than cross-sectional data. Unemployment at an older age among the more highly qualified and those with higher cognitive function scores may represent a stressful exposure that is more unexpected or more difficult to cope with than unemployment experienced among men with fewer qualifications or lower cognitive function scores, as suggested by the higher levels of unemployment-related psychological distress observed among white-collar workers. ${ }^{8}$ As we are concerned with unemployment as a marker of socioeconomic adversity, we did not adjust for other contemporaneous economic measures collinear with unemployment. The earlier research used diagnoses as the outcome ${ }^{5-7}$ and the results could theoretically have been influenced by more highly educated individuals seeking healthcare: the use of mortality in this study is not at a similar risk of bias through health service use.

It has long been observed that suicide rates increased both during periods of economic recession and also during phases of rapid economic growth, arguing that weakened social norms, rather than poverty alone, reduces social cohesion and thus increases suicide risk. ${ }^{18}$ A sense of coherence is relevant to an individual's adaptive capacity for social stress ${ }^{19}$ and unemployment may be damaging in this respect. Those with higher cognitive function and qualifications, signalling more advantages in earlier life, may be less well adapted to coping with unemployment-related stress. ${ }^{6} 7$ This theoretical framework not only potentially explains associations with suicide (the risk of which can vary by age $\mathrm{e}^{20}$ ) but also other causes of mortality, as our results are similar after exclusion of suicide. Poorer adaptation to social adversity has also been linked to an increased risk of stroke, ${ }^{21}$ indicating effects on the cardiovascular and possibly other systems.

Interaction analysis confirmed that the pattern of risk changed between the periods such that the greater risk of mortality among men with better cognition and qualifications who experienced unemployment at an older age was disproportionately higher (a multiplicative effect). Older people who have less possibility to return to work may find the consequence of the associated economic adversity more challenging, ${ }^{9}$ particularly during a period of economic contraction, despite the resources signalled by higher cognition and qualifications. This unemployment-associated risk of ill health may continue to increase with age.

Health selection can help to explain associations between unemployment and disease. ${ }^{22}$ Direct health selection is where pre-existing illness increases the risk of unemployment. We tackled this by excluding men with disability and sickness benefits at study entry and adjusting for chronic medical conditions diagnosed in adolescence. Additionally, we excluded events (deaths) in the initial years of follow-up after unemployment to allow the selection to 'wear off' when a high proportion of those with the most serious diseases predating unemployment are expected to die, ${ }^{16}$ as used in other studies of unemployment and mortality, including a previous study of unemployment in Sweden. ${ }^{17}$ The earlier Swedish study presented evidence of direct health selection as there was statistically significant excess mortality in the first 4 years following unemployment but not subsequently. ${ }^{17}$ Therefore, we excluded the first 4 years of follow-up in a subanalysis. Even though the men who experienced unemployment in the second period of our study may have been selected more on grounds of 
health, our procedures to tackle direct selection make this unlikely as an explanation for the reversal of the unemployment-mortality gradient by cognition or education.

Indirect health selection is where personal characteristics linked with raised unemployment risk are also risks for poor health. ${ }^{22}{ }^{23}$ We adjusted for a variety of measures relevant to future health and mortality risk, including chronic illnesses, height, ${ }^{24}$ blood pressure, ${ }^{10}$ BMI, ${ }^{25}{ }^{26}$ cognition, ${ }^{23}$ markers of physical fitness ${ }^{26}$ and stress resilience. Men with the most severe disabilities or chronic illness preventing military service would not have undergone some of the tests at conscription and are thus not included in the analysis. Indirect health selection is unlikely to explain the disappearance at a later age of the relatively protective association with higher qualifications and cognition, as the opposite effect might be expected.

It should be emphasised that unemployment remained less common among the more highly educated men and those with higher cognitive function. This means that support and benefits will remain a bigger issue for the less highly qualified and more disadvantaged. Unemployment can result in persistent disadvantage, including through subsequent unstable employment, ${ }^{27-29}$ so that when experienced at an earlier age, it can cause harm across an entire adult life. While it remains possible that earlier exit from the labour market helps to explain these results, it does not alter the fact that unemployment among older men is relatively more damaging across the social spectrum, suggesting that this is a 'critical period' where interventions might be focused. ${ }^{30}$

The experience of unemployment can contribute to the risk of ill health through several mechanisms. ${ }^{1}$ Behavioural change following unemployment, such as an increase in smoking (or failure to give up) and an unhealthy diet, ${ }^{27}$ can increase the risk of cardiovascular disease and cancer. The financial disadvantage associated with unemployment can persist even after finding a new $\mathrm{job}^{27}$ and the association of poverty with mortality is well known. ${ }^{31}$ Depression and stress resulting from unemployment are also likely to be relevant, as they may raise mortality risk through behavioural and possibly systemic mechanisms. ${ }^{32}$ Stressful events and circumstances have been linked to an increase in mortality due to suicide and cardiovascular disease. ${ }^{33}$ The mechanisms linking cognitive function and education with mortality may not be identical, ${ }^{2}$ but the pattern of unemployment-related mortality risk is similar when stratified by cognition or education.

\section{Limitations}

The potential limitations of the study include its inclusion of only men, as women can also be affected adversely by unemployment. This was necessary as the detailed baseline data on health and function were collected during military conscription, which at the time was only available to men. Disentangling age and period effects in a single cohort can be problematic. The two time points differed in unemployment rate: the proportion unemployed was larger in the second period, thus possibly altering the selection effects. To tackle the possible selection bias, we adjusted for multiple markers of susceptibility. We also excluded events during the first part of the follow-up period to allow direct health selection to 'wear off'. The study focused on unemployment only at two time points and these represent times when Sweden was entering periods of economic contraction: these were chosen when the study was designed and information on unemployment at other times was not included in our dataset. These measures will underestimate the experience of unemployment and not take duration of unemployment into account. This is likely to make our estimates less precise rather than creating spurious results. There is a greater possibility of prior unemployment in the later period and thus greater unemployment duration, but our adjustment for previous unemployment did not indicate that this was driving the results. The focus of the study was on mortality as an objective endpoint. While this will underestimate the damage to health associated with unemployment substantially, it makes it more feasible to tackle the effects of direct health selection through 'selection wearing off' analysis. Less serious health events associated with unemployment will not be captured by a study of mortality. Mortality is more likely to occur at older ages and causes of mortality vary by age.

Unemployment during periods of economic contraction is associated with raised mortality that may not be explained fully by direct or indirect health selection into unemployment. With increasing age, the experience of unemployment may be unexpectedly harmful to those with better cognition, higher qualifications and associated resources. This highlights the importance of supporting the entire population, which experiences unemployment during a recession, and the greater vulnerability of older workers.

\section{Author affiliations}

${ }^{1}$ Clinical Epidemiology and Biostatistics, Örebro University Hospital, Örebro, Sweden

${ }^{2}$ School of Health and Medical Sciences, Örebro University, Örebro, Sweden ${ }^{3}$ Clinical Epidemiology Unit, Karolinska University Hospital, Karolinska Institutet, Stockholm, Sweden

${ }^{4}$ Stress Research Institute, Stockholm University, Stockholm, Sweden ${ }^{5}$ Department of Medicine, Örebro University Hospital, Örebro, Sweden ${ }^{6}$ Department of Primary Care and Public Health, School of Public Health, Imperial College London, London, UK

Acknowledgements The authors would like to thank Oula Hussein who helped to prepare the tables.

Contributors SM, AM, WO and DB developed the hypotheses and designed the study. RU and AM prepared the data and conducted the analysis. AM, RU, WO and POS identified and clarified the codes and measures required for the analysis. SM drafted the manuscript and all contributors were involved in critical editing. SM is the guarantor. All authors read and approved the final version of the manuscript. 
Funding This study received support from the Economic and Social Research Council (ESRC) grant RES-596-28-0001 to the International Centre for Life Course Studies and Strategic funding from Örebro University.

Competing interests SM received research grants from ESRC and Örebro University to support this work.

Ethics approval Uppsala Regional Ethics Committee.

Provenance and peer review Not commissioned; externally peer reviewed.

Data sharing statement No additional data are available, as the ethical permission does not allow for provision of data to individuals not in the research group.

\section{REFERENCES}

1. Janlert U, Hammarstrom A. Which theory is best? Explanatory models of the relationship between unemployment and health. BMC Public Health 2009;9:235.

2. Lager A, Bremberg S, Vagero D. The association of early IQ and education with mortality: 65 year longitudinal study in Malmo, Sweden. BMJ 2009;339:b5282.

3. Calvin CM, Deary IJ, Fenton $C$, et al. Intelligence in youth and all-cause-mortality: systematic review with meta-analysis. Int $J$ Epidemiol 2011;40:626-44.

4. Batty GD, Wennerstad KM, Smith GD, et al. IQ in early adulthood and mortality by middle age: cohort study of 1 million Swedish men. Epidemiology 2009;20:100-9.

5. Osika W, Ehlin A, Montgomery SM. Does height modify the risk of angina associated with economic adversity? Econ Hum Biol 2006;4:398-411.

6. Montgomery SM, Netuveli G, Hildon Z, et al. Does financial disadvantage at older ages eliminate the potential for better health? J Epidemiol Community Health 2007;61:891-5.

7. Osika W, Montgomery SM. Economic disadvantage modifies the association of height with low mood in the US, 2004: the disappointment paradox. Econ Hum Biol 2008;6:95-107.

8. D'Arcy C, Siddique CM. Unemployment and health: an analysis of "Canada Health Survey" data. Int J Health Serv 1985;15:609-35.

9. McKee M, Stuckler D. Older people in the UK: under attack from all directions. Age Ageing 2013;42:11-13.

10. Sundstrom J, Neovius $M$, Tynelius $P$, et al. Association of blood pressure in late adolescence with subsequent mortality: cohort study of Swedish male conscripts. BMJ 2011;342:d643.

11. Whitley E, Batty GD, Gale CR, et al. Intelligence in early adulthood and subsequent risk of unintentional injury over two decades: cohor study of 1109475 Swedish men. J Epidemiol Community Health 2010;64:419-25.

12. Lothigius J. Verksamhetsinstruktion för Psykologer VIP95 (Psychological Test Manual used by the Swedish National Service Administration VIP95). Karlstad, 1995.

13. Nilsson PM, Nyberg P, Ostergren PO. Increased susceptibility to stress at a psychological assessment of stress tolerance is associated with impaired fetal growth. Int $J$ Epidemiol 2001;30:75-80.

14. Statistics Sweden. http://www.scb.se/default 2154.aspx (accessed 25 Mar 2013).
15. The Cause of Death Register. http://www.socialstyrelsen.se/register/ dodsorsaksregistret (accessed 25 Mar 2013).

16. Moser KA, Goldblatt PO, Fox AJ, et al. Unemployment and mortality: comparison of the 1971 and 1981 longitudinal study census samples. BMJ 1987;294:86-90.

17. Lundin A, Lundberg I, Hallsten L, et al. Unemployment and mortality -a longitudinal prospective study on selection and causation in 49321 Swedish middle-aged men. J Epidemiol Community Health 2010;64:22-8.

18. Durkheim É. Suicide: a study in sociology; translated by John A Spaulding and George Simpson. New York: The Free Press of Glencoe, 1951.

19. Surtees PG, Wainwright NW, Khaw KT. Resilience, misfortune, and mortality: evidence that sense of coherence is a marker of social stress adaptive capacity. J Psychosom Res 2006;61:221-7.

20. Varnik P. Suicide in the world. Int $J$ Environ Res Public Health 2012:9:760-71.

21. Surtees PG, Wainwright NW, Luben RL, et al. Adaptation to social adversity is associated with stroke incidence: evidence from the EPIC-Norfolk prospective cohort study. Stroke 2007;38:1447-53

22. Bartley M, Ferrie J. Do we need to worry about the health effects of unemployment? J Epidemiol Community Health 2010;64:5-6.

23. Montgomery SM, Bartley MJ, Cook DG, et al. Health and social precursors of unemployment in young men in Great Britain. $J$ Epidemiol Community Health 1996;50:415-22.

24. Magnusson PK, Gunnell D, Tynelius P, et al. Strong inverse association between height and suicide in a large cohort of Swedish men: evidence of early life origins of suicidal behavior? Am J Psychiatry 2005;162:1373-5.

25. Magnusson PK, Rasmussen F, Lawlor DA, et al. Association of body mass index with suicide mortality: a prospective cohort study of more than one million men. Am J Epidemiol 2006;163:1-8.

26. Bellocco R, Jia C, Ye W, et al. Effects of physical activity, body mass index, waist-to-hip ratio and waist circumference on total mortality risk in the Swedish National March Cohort. Eur J Epidemio 2010;25:777-88.

27. Wadsworth ME, Montgomery SM, Bartley MJ. The persisting effect of unemployment on health and social well-being in men early in working life. Soc Sci Med 1999;48:1491-9.

28. Virtanen P, Vahtera J, Kivimaki M, et al. Employment security and health. J Epidemiol Community Health 2002;56:569-74.

29. Ferrie JE, Shipley MJ, Stansfeld SA, et al. Effects of chronic job insecurity and change in job security on self reported health, minor psychiatric morbidity, physiological measures, and health related behaviours in British civil servants: the Whitehall II study. $J$ Epidemiol Community Health 2002;56:450-4.

30. Bartley M, Blane D, Montgomery S. Health and the life course: why safety nets matter. BMJ 1997;314:1194-6.

31. Thomas B, Dorling D, Smith GD. Inequalities in premature mortality in Britain: observational study from 1921 to 2007. BMJ 2010;341: c3639.

32. Cohen F, Kemeny ME, Zegans LS, et al. Immune function declines with unemployment and recovers after stressor termination. Psychosom Med 2007;69:225-34.

33. Fang F, Fall K, Mittleman MA, et al. Suicide and cardiovascular death after a cancer diagnosis. N Engl J Med 2012;366:1310-18 